\title{
Desempenho agronômico de cultivares de batata-doce (Ipomoea batatas) em Iporá -
}

\section{Goiás}

\author{
Agronomic performance of sweet potato cultivars (Ipomoea batatas) in Iporá -Goiás \\ Rendimiento agronómico de cultivares de camote (Ipomoea batatas) en Iporá -Goiás
}

Recebido: 13/05/2021 | Revisado: 22/05/2021 | Aceito: 01/06/2021 | Publicado: 14/06/2021

Talita Cavalcante Cajango

ORCID: https://orcid.org/0000-0003-3522-8155

Instituto Federal de Educação, Ciência e Tecnologia Goiano, Brasil

E-mail: talitacajango@gmail.com

Estenio Moreira Alves

ORCID: https://orcid.org/0000-0002-2208-7384 Instituto Federal de Educação, Ciência e Tecnologia Goiano, Brasil E-mail: estenio.moreira@ifgoiano.edu.br

Guido Calgaro Junior

ORCID: https://orcid.org/0000-0002-8082-0409 Instituto Federal de Educação, Ciência e Tecnologia Goiano, Brasil E-mail: guido.junior@ifgoiano.edu.br

Tiago do Prado Paim

ORCID: https://orcid.org/0000-0002-9486-7128 Instituto Federal de Educação, Ciência e Tecnologia Goiano, Brasil E-mail: tiago.paim@ifgoiano.edu.br

Flavio Lopes Claudio

ORCID: https://orcid.org/0000-0002-9664-1886 Instituto Federal de Educação, Ciência e Tecnologia Goiano, Brasil E-mail: flavio.claudio@ifgoiano.edu.br

\begin{abstract}
Resumo
O desempenho de diferentes genótipos é diferente conforme ambiente e processo produtivo empregado, conhecer esse comportamento é fundamental para obtenção de boas produtividades. Nesse sentido, objetivou-se avaliar o desempenho agronômico e produtivo de diferentes tipos de cultivares de batata-doce, visando a seleção de cultivares mais produtivos voltados a alimentação humana. Desenvolveu-se um experimento, no ano de 2014, composto por nove cultivares no delineamento em blocos casualizados (DBC), com três repetições. Avaliou-se as características de produtividade, formato da raiz, massa, comprimento, diâmetro e os resíduos, quantificando assim as raízes não comerciais. As cultivares Brazlandia Roxa, Rubssol, Brazlandia Branca, Beauregard e Princesa obtiveram maior desempenho agronômico. Dessa forma essas variedades não se diferiram e apresentaram características interessantes a serem exploradas para a produção destinada a alimentação humana pelo seu desempenho agronômico e de produção, porém a escolha deve ser levada em consideração a facilidade de implantação e o mercado consumidor que deseja atingir.
\end{abstract}

Palavras-chave: Comprimento; Diâmetro; Massa de raízes; Produtividade.

\begin{abstract}
The performance of different genotypes is different according to the environment and production process employed, knowing this behavior is fundamental to obtain good productivity. In this sense, the objective was to evaluate the agronomic and productive performance of different types of sweet potato cultivars, aiming at the selection of more productive cultivars focused on human food. An experiment was carried out in 2014, composed of nine cultivars in a randomized block design (DBC), with three replications. The characteristics of productivity, root shape, mass, length, diameter and residues were evaluated, thus quantifying the non-commercial roots. The cultivars Brazlandia Roxa, Rubssol, Brazlandia Branca, Beauregard and Princess obtained higher agronomic performance. Thus, these varieties did not differ and presented interesting characteristics to be explored for production destined to human food for their agronomic and production performance, but the choice should be taken into account the ease of implantation and the consumer market that it wishes to achieve.
\end{abstract}

Keywords: Length; Diameter; Root mass; Productivity.

\section{Resumen}

El rendimiento de los diferentes genotipos es diferente según el entorno y el proceso de producción empleados, sabiendo que este comportamiento es fundamental para obtener una buena productividad. En este sentido, el objetivo era evaluar el rendimiento agronómico y productivo de los diferentes tipos de cultivares de camote, con el objetivo de 
seleccionar cultivares más productivos enfocados a la alimentación humana. Un experimento se llevó a cabo en 2014, compuesto por nueve cultivares en un diseño de bloque aleatorio (DBC), con tres réplicas. Se evaluaron las características de productividad, forma de la raíz, masa, longitud, diámetro y residuos, cuantificando así las raíces no comerciales. Los cultivares Brazlandia Roxa, Rubssol, Brazlandia Branca, Beauregard y Princesa obtuvieron un mayor rendimiento agronómico. Por lo tanto, estas variedades no difieren y presentan características interesantes que deben explorarse para la producción destinada a alimentos humanos por su rendimiento agronómico y de producción, pero la elección debe tenerse en cuenta la facilidad de implantación y el mercado de consumo que desea lograr.

Palabras clave: Longitude; Diâmetro; Masa radicular; Productividad.

\section{Introdução}

A batata-doce [Ipomoea batatas (L.) Lam.] é uma espécie de hortaliça tuberosa que se destaca pela sua rusticidade, facilidade de cultivo, resistência a pragas, ampla adaptação, alta tolerância à seca, ampla adaptação edafoclimática, cultura está bastante disseminada de forma geral, pois pode ser usada para vários fins, como para a alimentação humana, animal e industrial. Com baixo custo de produção é, portanto, cultivada por produtores de comunidades locais, contribuindo com a economia e suprimento alimentar das populações mais pobres (Souza, 2000; Oliveira et al., 2005ab; Montes et al., 2006).

A batata-doce é uma das plantas de raiz tuberosa com grande importância econômica-social, participando no suprimento de calorias, vitaminas e minerais na alimentação humana. As ramas e raízes tuberosas são largamente utilizadas na alimentação humana, animal e como matéria-prima (Cardoso et al., 2005; Figueredo et al. 2012). É uma das hortaliças mais cultivada pelo homem nas regiões tropicais e subtropicais, e seu cultivo se destina às mais diversas formas de utilização. A cultura da batata-doce é altamente responsiva com relação a fertilidade (Bregagnoli, et al., 2003). Embora essa hortaliça responda bem ao uso de nutrientes no solo, deve-se estar atento a adição em excesso, em especial o nitrogênio e potássio (Barcelos et al., 2007; Miranda, 2003).

O Brasil nos últimos 10 anos, empregou em média aproximadamente 43.161 hectares ao cultivo da batata-doce. Sendo, a região Nordeste responsável por 44,2\% dessa área cultivada. Durante o período de 2004 a 2014, o valor monetário médio anual do Brasil com a cultura da batata foi de aproximadamente 312 milhões de reais, contudo a limitação do potencial produtivo, faz com que a região sul represente $50 \%$ deste montante, seguido pela região nordeste com $29,45 \%$ de toda a receita produzida. Embora menor o montante, a região nordeste, cujas condições climáticas são mais áridas, possui importância social para a população.

A época de plantio da batata-doce é bastante determinada em função dos elementos climáticos, que tem influência sobre o crescimento e desenvolvimento e produtividade da cultura. A produtividade média de batata-doce no Brasil é baixa. Entretanto, utilizando o manejo adequado pode-se atingir a produtividades entre 25 a 30 Ton ha $^{-1}$ dentro de quatro a cinco meses de cultivo, podendo ainda ser superior a $40 \mathrm{Ton} \mathrm{ha}^{-1}$ (Andrade Júnior et al, 2009, 2012).

Silva et al. (2002), relatam que na Paraíba a batata-doce assume grande importância social, pois a produção mesmo sendo pequena devido ao baixo investimento que se utiliza, constitui uma fonte de alimento energético, uma vez que suas raízes contêm importantes teores de vitaminas e de proteína, levando-se em conta a grande limitação na disponibilidade de outros alimentos em períodos críticos de estiagem prolongada.

Portanto, para melhorar as condições de produção, além do manejo correto, adubações e os demais tratos culturais, faz-se necessário explorar o desempenho agronômico das cultivares de batata-doce, quanto a caracteres relacionados com o rendimento de raízes, produtividade e os caracteres de herança quantitativa e de forte influência ambiental (Silva et al., 2012). A eficiência do potencial produtivo das cultivares é relevante para produzir energia por unidade de área e tempo.

$\mathrm{O}$ aumento do rendimento de qualidade de raízes da batata-doce, podem se constituir em importantes ferramentas para melhorar a condições socioeconômicas da região. Já que é uma hortaliça que se destaca pela versatilidade no uso, pelo seu cultivo ser relativamente fácil e barato, o que, juntamente com sua adaptabilidade a variadas condições edafoclimáticas, 
viabiliza sua produção pelos agricultores familiares (Andrade Júnior et al., 2012).

Neste contexto, objetivou-se avaliar o potencial produtivo de diferentes cultivares de batata doce, visando a seleção de materiais genéticos mais produtivos para o uso na alimentação humana, cujos resultados podem refletir em ganhos na sustentabilidade agrícola e consequentemente socioeconômicos.

\section{Metodologia}

O experimento foi conduzido no setor de olericultura da Fazenda Escola do Instituto Federal Goiano, Campus Iporá, região oeste de Goiás. A área experimental possui $573 \mathrm{~m}$ de altitude, com solo classificado como Cambissolo (Cambisols) (Embrapa, 2013). Na região oeste de Goiás, situado a latitude $-16.423 .059^{\circ}$ e longitude $-51.148 .801^{\circ}$.

As condições meteorológicas foram registadas por estação automática (A028) INMET conforme demonstrado na Figura 1 entre fevereiro e agosto em 2014. Os resultados da análise físico-química do solo utilizado no experimento (Tabela 1).

Figura 1- Precipitação $(\mathrm{mm})$ e temperaturas mínima, máxima e média $\left({ }^{\circ} \mathrm{C}\right)$ registradas durante a condução do experimento. Iporá, Goiás, Brasil.

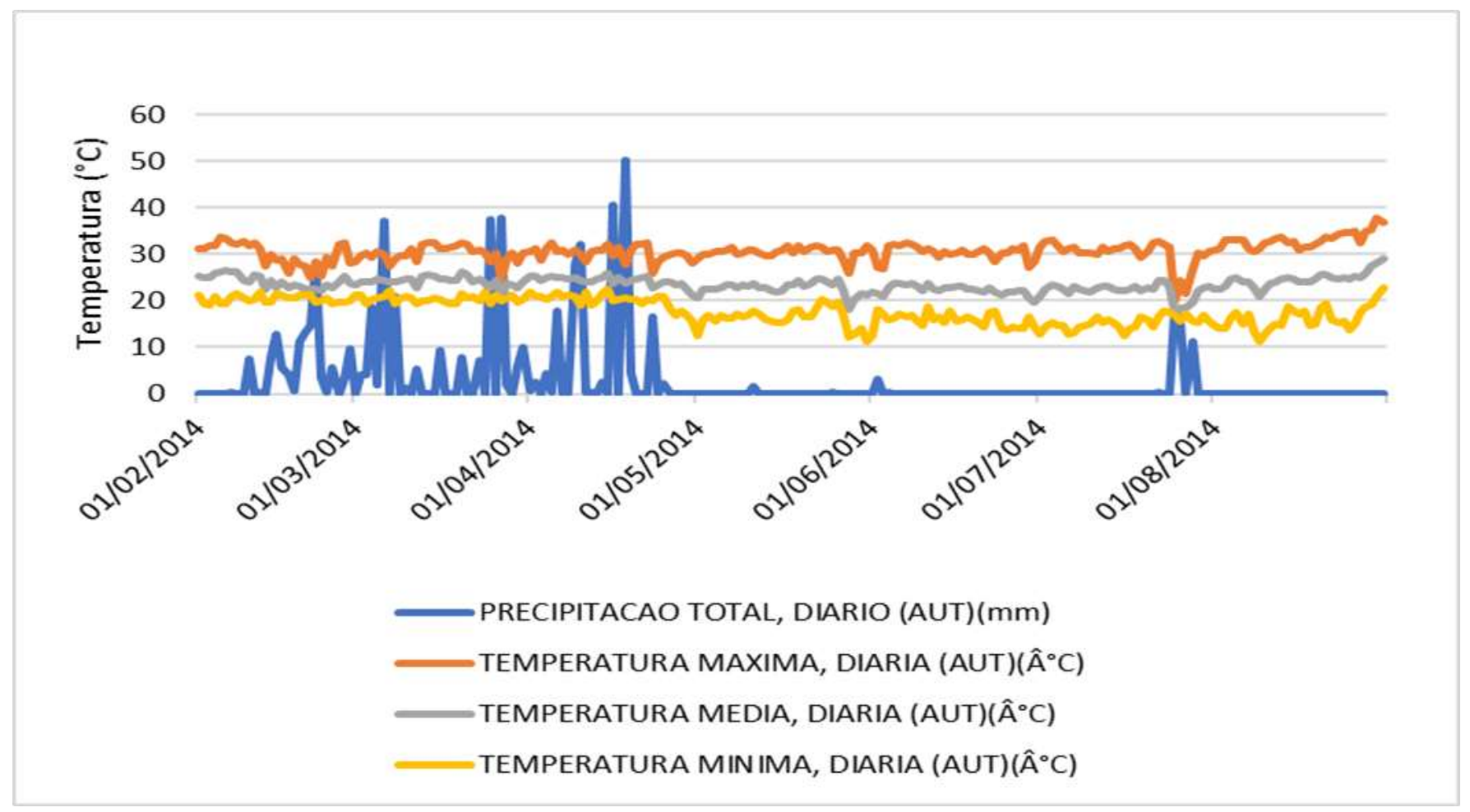

Fonte: INMET (2014).

O experimento foi implementado 01/02/2014 até 30/08/2014, sendo o plantio dia 14/02/2014 e a colheita seis meses após. Houve a realização dos tratos culturais no solo, previamente com a capina manual, irrigação, gradagem e sulcagem e adubação de base. 
Tabela 1 - Análise físico-química do solo utilizado no experimento. Iporá, Goiás, 2014.

\begin{tabular}{|c|c|c|c|c|c|c|c|c|c|c|}
\hline \multirow{2}{*}{$\begin{array}{c}\text { pH } \\
\left(\mathrm{CaCl}_{2}\right)\end{array}$} & MO & Ca & Mg & $\mathbf{K}$ & $\mathbf{H}+\mathbf{A l}$ & CTC & \multirow{2}{*}{$\begin{array}{c}\mathbf{P} * \\
\mathrm{mg} \mathrm{dm}{ }^{-3}\end{array}$} & Argila & Silte & Areia \\
\hline & $\%$ & 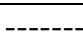 & 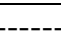 & $\mathrm{nol}^{\mathrm{c}}$ & $-2-1$ & ------- & & \multicolumn{3}{|c|}{---------- \% --- } \\
\hline 5,5 & 2,0 & 3,5 & 1,0 & 0,4 & 1,8 & 6,73 & 7,0 & 17,00 & 16,00 & 67,00 \\
\hline
\end{tabular}

*Melich I. Fonte: Dados dos autores.

Efetuou-se a correção, adubação de base e de cobertura conforme Ribeiro et al. (1999), elevando a saturação por bases a $60 \%$ e o teor do magnésio a um mínimo de $1,0 \mathrm{cmol}_{\mathrm{c}} \mathrm{dm}^{-3}$. Aplicou-se na adubação de base $180,0 \mathrm{~g}$ de superfosfato simples, 30,0 g de cloreto de potássio, 20,0 g de ureia e 2,0 L de esterco curtido por cova. A primeira adubação de cobertura foi 28 dias após a semeadura (DAS) com 50,0 g de sulfato de amônio por cova. Já a segunda adubação de cobertura foi 42 DAS com 20,0 $\mathrm{g}$ de ureia e 5,0 g de cloreto de potássio por cova.

Os tratamentos foram compostos por nove cultivares de batata doce sendo: Beauregard, BRS Rubissol, BRS Cuiá, BRS Amélia, Princesa, Brasilândia, Roxa, Brasilândia Branca, Brasilândia Rosada, em acesso local, o projeto experimental foi de blocos casualizado DBC, com três repetições.

O plantio foi realizado dia 14-02-2014, em camalhões espaçados entre si a 0,80 m. A ramas foram plantadas respeitando o espaçamento de $0,40 \mathrm{~m}$ entre rama nos camalhões.

Cada parcela foi composta de cinco sulcos com cinco plantas em cada camalhão, dentre essas a área utilizada foi a parte central composta por nove plantas, sendo as três centrais dos três camalhões centrais. As parcelas, portanto, possuíam 2,0 m de comprimento por 4,0 m de largura, com camalhões confeccionados com $25-30 \mathrm{~cm}$ de altura.

Utilizou-se um sistema de irrigação por aspersão sendo ligado somente para manter o solo com a capacidade de campo. Na ocasião da colheita 150 dias após o plantio, realizada no dia 14-07-2014, foram avaliadas as variáveis ( de produtividade total de raízes comerciais fresca (PRO - Ton ha ${ }^{-1}$ ), produtividade total de raízes não comerciais (Resíduos) (RES - Ton $\mathrm{ha}^{-1}$ ), representatividade percentual das raízes não comerciais (RES \%) (RESENDE, 2000), formato das raízes, massa média das raízes (MAS - g), comprimento (COM - cm) e diâmetro (DIA - cm).

Os dados foram submetidos a ANAVA, havendo efeitos significativos foram submetidos a comparação entre as medias pelo teste de Duncan $(\mathrm{P}<0,05)$.

\section{Resultados e Discussão}

Analisando as variedades de acordo com a tabela 2 em relação a produtividade (Ton ha ${ }^{-1}$ ) verificamos que a variedade Beauregard obteve melhor produtividade juntamente com as variedades Brazlândia Roxa, Amelia, Rubssol, Brazlândia Branca e Princesa (34,09 - 22,22 Ton ha ${ }^{-1}$ ). De acordo Erpen et al. (2013), a variedade Princesa apresentou produtividade de matéria fresca de raízes comerciais igual a 22,62 ton ha ${ }^{-1}$, em 264 dias de cultivo. Todavia, é importante ressaltar que o cultivo foi implantado e conduzido durante época do ano desfavorável a redução do período de plantio-tuberização, visto que a batata doce é influenciada pelo fotoperíodo.

Ressalta-se ainda que a adubação potássica foi elevada, quando comparada a dose máxima técnica descrita por Brito et al. (2006). A amplitude de doses avaliadas por Brito et al., (2006), ficou abaixo das doses aplicadas neste ensaio, o que provavelmente limitou o potencial produtivo. Entretanto, produtividades similares foram obtidas por Andrade Junior et al (2009), cujas recomendação de adubação potássica utilizou o mesmo padrão deste trabalho.

Observa-se que a produtividade determinada no ensaio é superior a determinada por Oliveira et al. (2005 ab), quando avaliado efeito de diferentes doses de fósforo e nitrogênio. Há, potencial de altas produtividades para o cultivo da cultura, pois mesmo produtividades mais elevadas assemelham aos resultados aqui apresentados (Rós et al., 2013). 
Os resultados obtidos são corroborados por Rós et al., (2013), pois, quanto maior o tempo de cultivo, maior a produtividade e maior a massa das raízes. No tocante ao manejo de nitrogênio os resultados obtidos foram baixos quando comparados as produtividades de raízes descritas por Santos Neto et al., (2017), é provável que as condições regionais possam ter contribuído para redução da eficiência no uso de nitrogênio. Assim, há necessidade de trabalhos com objetivo de conhecer o comportamento na região do uso de doses de nitrogênio superiores as avaliadas por Santos Neto et al., (2017).

Já a variedade de batata-doce que apresentou menor desempenho de produtividade comercial foi o acesso local seguido pela variedade Cuiá. Já a variedade Brazlândia Rosada apresentou produtividade intermediária dentre os cultivares avaliados. O acesso local avaliado possui formato de raiz elíptico redondo e apresentou o maior índice percentual de produtividade não comercial. Já a Cuiá mesmo com baixo desempenho deteve de apenas 7\% de resíduo, com seu formato de raiz redondo.

Tabela 2 - Características do formato, produtividade de raízes comerciais (PRO) (Ton ha ${ }^{-1}$ ), produtividade de raízes não comerciais (Resíduo) (RES) $\left(\right.$ Ton ha ${ }^{-1}$ ) e porcentagem de raízes não comerciais de variedades de batata-doce. Iporá, Goiás, 2014.

\begin{tabular}{|c|c|c|c|c|}
\hline Variedades & PRO (Ton ha') & RES (Ton ha') & RES (\%) & FORMATO \\
\hline Brazlandia Roxa & $24,53 \mathrm{ab}$ & $2,83 \mathrm{ab}$ & $11 \mathrm{bc}$ & Longo Irregular \\
\hline Amelia & $25,54 \mathrm{ab}$ & $2,89 \mathrm{ab}$ & $13 \mathrm{~b}$ & Elíptico \\
\hline Rubssol & $22,22 \mathrm{ab}$ & $0,99 \mathrm{c}$ & $5 \mathrm{bc}$ & Elíptico Redondo \\
\hline Brazlandia Rosada & $17,31 \mathrm{bc}$ & $1,49 \mathrm{bc}$ & $8 \mathrm{bc}$ & Longo Irregular \\
\hline Brazlandia Branca & $30,43 \mathrm{ab}$ & $1,06 \mathrm{c}$ & $3 c$ & Redondo \\
\hline Acesso Local & $4,09 \mathrm{~d}$ & $1,87 \mathrm{ab}$ & $33 \mathrm{a}$ & Elíptico redondo \\
\hline Beauregard & 34,09 a & $2,60 \mathrm{ab}$ & $8 \mathrm{bc}$ & Elíptico Redondo \\
\hline Cuiá & $16,24 \mathrm{~cd}$ & $1,57 \mathrm{c}$ & $7 \mathrm{bc}$ & Redondo \\
\hline Princesa & $31,38 \mathrm{ab}$ & $1,96 \mathrm{a}$ & $9 \mathrm{bc}$ & Longo Irregular \\
\hline CV (\%) & 32,73 & 37,82 & 28,25 & - \\
\hline
\end{tabular}

Médias letras distintas na coluna representa diferenças significativas entre as médias pelo teste "Duncan" $(\mathrm{p} \leq 0,05)$.

Fonte: Dados dos autores.

De acordo com a (tabela 03), a variedade Brazlândia Branca apresentou as raízes de maior massa juntamente com Rubssol Princesa, o que pode ser crucial na aceitação ou não pelo mercado consumidor. No que diz respeito ao comprimento, há destaque para as variedades Amelia, Brazlândia Rosada e Princesa. A massa média das raízes situou-se no Tipo 1 (100 - 400 g), comportamento similar ao determinado por Resende, (2000), quando realizada a colheita aos 150 dias após plantio. 
Tabela 3 - Média da massa das raízes (MAS), diâmetro (DIA) e comprimento (COM) de variedades de batata-doce. Iporá, Goiás, 2014.

\begin{tabular}{|c|c|c|c|}
\hline Variedades & $\operatorname{MAS}(\mathrm{g})$ & $\operatorname{COM}(\mathrm{cm})$ & DIA (cm) \\
\hline Brazlandia Roxa & $237,93 \mathrm{~b}$ & $13,83 \mathrm{bc}$ & $4,80 \mathrm{c}$ \\
\hline Amelia & $255,43 \mathrm{~b}$ & $15,73 \mathrm{ab}$ & $5,43 \mathrm{bc}$ \\
\hline Rubssol & $302,40 \mathrm{ab}$ & $12,00 \mathrm{~cd}$ & $6,00 \mathrm{ab}$ \\
\hline Brazlandia Rosada & $256,50 \mathrm{~b}$ & $15,63 \mathrm{ab}$ & $5,27 \mathrm{bc}$ \\
\hline Brazlandia Branca & 399,63 a & $11,67 \mathrm{~cd}$ & $6,87 \mathrm{a}$ \\
\hline Acesso Local & $116,47 \mathrm{c}$ & $9,03 \mathrm{e}$ & $5,40 \mathrm{bc}$ \\
\hline Beauregard & $272,17 \mathrm{~b}$ & $13,73 \mathrm{bc}$ & $6,13 \mathrm{ab}$ \\
\hline Cuiá & $262,87 \mathrm{~b}$ & $9,27 \mathrm{de}$ & $6,93 \mathrm{a}$ \\
\hline Princesa & $319,00 \mathrm{ab}$ & $17,07 \mathrm{a}$ & $5,07 \mathrm{bc}$ \\
\hline CV $(\%)$ & 20,29 & 11,69 & 11,16 \\
\hline
\end{tabular}

Médias letras distintas na coluna representa diferenças significativas entre as médias pelo teste "Duncan" $(\mathrm{p} \leq 0,05)$.

Fonte: Dados dos autores.

Observa-se que nenhum dos cultivares apresentou-se de forma combinada superior na massa, comprimento e diâmetro simultaneamente. Esta alternância no topo destas características biométricas das raízes diferenciam as variedades frente a aceitação do consumidor final, influenciado fortemente pelo regionalismo do consumo.

$\mathrm{Na}$ comparação da produtividade de raízes comerciais, dentre as noves variedades testadas, é notório que as variedades Brazlândia Roxa, Amelia, Rubssol, Braslândia Branca, Beauregard e Princesa são as melhores opções agronomicamente para a região. Entretanto, se a preferência for por raízes mais longas recomenda-se Amelia e Princesa. No caso de mais pesadas Rubssol, Braslândia Branca e Princesa. Já para as de calibre maiores as variedades mais recomendadas são Rubssol, Braslândia Branca e Beauregard.

Dentre os cultivares avaliados, a Brazlândia Rosada, Acesso Local e Cuiá apresentaram o pior desempenho agronômico em relação as demais, conforme as condições que foram submetidas.

\section{Conclusão}

Conclui-se que as variedades Brazlândia Roxa, Rubssol, Brazlândia Branca, Beauregard e Princesa possui potencial agronômico de produção de raízes para a alimentação humana. Todavia, a escolha da variedade mais produtiva deve levar em consideração o potencial de comercialização, bem como a facilidade acesso as ramas para plantio.

É pertinente que trabalhos futuros avalie dentre as seis variedades mais produtivas, as variedades que possuam maior preferência do mercado consumidor regional.

\section{Agradecimentos}

Agradecemos ao Instituto Federal Goiano, Campus Iporá pelo financiamento da execução do projeto e a Embrapa Hortaliças (CNPH) pela doação das mudas para implantação do ensaio.

\section{Referências}

Andrade Júnior, V. C. Viana, D. J. S. Fernandes, J. S. C. Figueiredo, J. A. Nunes, U. R. \& Neiva, I. P. (2009). Selection of sweet potato clones for the region Alto Vale do Jequitinhonha. Horticultura Brasileira, 27: 389-393. http://dx.doi.org/10.1590/S0102-05362009000300024 
Barcelos, D. M. Garcia, A \& Maciel Junior, V. A. (2007). Análise de crescimento da cultura da batata submetida ao parcelamento da adubação nitrogenada em cobertura, em um latossolo vermelho-amarelo. Ciência e Agrotecnologia, 31 (1): 21-27. http://dx.doi.org/10.1590/S1413-70542007000100003

Bregagnoli, M. Bregagnoli, F. C. R. Minami, K. Gratieri, L. A. \& Minchillo, M. (2003). Análise bromatológica de sete cultivares de batata (Solanum tuberosum L.) cultivadas na safra de verão no sul de Minas Gerais. Horticultura Brasileira, 21: 387-387.

Brito. C. H; Oliveira, A. P; Alves, A. U; Dorneles, C. S. M; Santos, J. F. \& Nóbrega, J. P. R. (2006). Produtividade da batata-doce em função de doses de $\mathrm{K}_{2} \mathrm{O}$ em solo arenoso. Horticultura Brasileira, 24: 320-323.

Cardoso, A. D. Viana, A. E. S. Ramos, P. A. S. Matsumoto, S. N. Amaral, C. L. F. Sediyama, T. \& Morais, O. M. (2005). Avaliação de clones de batata-doce em Vitória da conquista. Horticultura Brasileira, 23 (4): 911-914. http://dx.doi.org/10.1590/S0102-05362005000400009

EMBRAPA. (2013). Sistema Brasileiro de Classificação do Solo, (3a ed.), EMBRAPA, 353p.

Erpen, L. Streck, N. A. Uhlmann, L.O. Freitas, C. P. d. O. \& Andriolo, J. L. (2013). Tuberização e produtividade de batata-doce em função de datas de plantio em clima subtropical. Bragantia, 72(4), 396-402. https://dx.doi.org/10.1590/brag.2013.050

Figueiredo, J. A; Andrade Junior, V. C; Perreia, R. C; Ribeiro, K. G; Viana, D. J. S. \& Neiva, I.P. (2012). Avaliação de silagens de ramas de batata-doce. Horticultura Brasileira, 30: 708-712.

Koche, J. C. (2011). Fundamentos de metodologia científica. Vozes. 182p.

Miranda, J. E. C. (2003). EMBRAPA-CNPH. Batata-doce. Recuperado em: 10 de junho de 2020 de: http://www.cnph.embrapa.br/cultivares/batata-doce.htm

Montes, S. M. N. M. Firetti, R. Golla, A. R. \& Tarsitano, M. A. A. (2006). Custos e rentabilidade da batata-doce (Ipomoea batatas L.) na região oeste do estado de São Paulo. Informações Econômicas. 36 (4): 15-23.

Oliveira, A. P. Oliveira, M. R. T. Barbosa, J. A. Silva, G. G. Nogueira, D. H. Moura, M. F. \& Braz, M. S. S. (2005a). Rendimento e qualidade de raízes de batata-doce adubada com níveis de ureia. Horticultura Brasileira. 23: 925-928.

Oliveira, A. P. Silva, J. E. L. Pereira, W. E. \& Barbosa, L. J. N. (2005b). Produção de batata-doce em função de doses de $\mathrm{P}_{2} \mathrm{O}_{5}$ em dois sistemas de plantio. Horticultura Brasileira. 23: 768-772. http://dx.doi.org/10.1590/S0102-05362005000300016

Resende, G. M. Características produtivas de cultivares de batata-doce em duas épocas de colheita, em Porteirinha - MG. Horticultura Brasileira, v.18, p.6871, 2000. http://dx.doi.org/10.1590/S0102-05362000000100016

Ribeiro, A. C. Guimarães, P. T. G. \& Alvarez V. V. H. (1999). Recomendações para o uso de corretivos e fertilizantes em Minas Gerais: $5^{a}$ aproximação. Viçosa, MG: Comissão de Fertilidade do solo do Estado de Minas Gerais. 180p.

Santos Neto, A. R; Silva, T. O.; Blank, A. F; Silva, J. O. \& Araújo Filho, R. N. (2017). Produtividade de clones de batata doce em função de doses de nitrogênio. Horticultura Brasileira, 35: 445-452. http://dx.doi.org/10.1590/S0102-053620170322

Silva, G. O. Ponijaleki, R. \& Suinaga, F. A. (2012). Divergência genética entre acessos de batata-doce utilizando caracteres fenotípicos de raiz. Horticultura Brasileira. 30: 595-599. http://dx.doi.org/10.1590/S0102-05362012000400006

Rós, Amarílis, Tavares Filho, João, \& Barbosa, Graziela Moraes de Cesare. (2013). Produtividade da cultura da batata-doce em diferentes sistemas de preparo do solo. Bragantia, 72(2), 140-145. https://doi.org/10.1590/S0006-87052013000200005

Silva, J. B. C. Lopes, C. A. \& Matias, E. C. A. (2002). Tuberosas amiláceas latino americano, a cultura da batata-doce. Cerada, M. P. Agricultura. São Paulo Cargill. 2: 449-503.

Souza, A. B. (2000). Avaliação de cultivares de batata-doce quanto a atributos agronômicos desejáveis. Ciência e Agrotecnologia. 24(4): 841-845. 